\title{
Autophagic degradation of epidermal growth factor receptor in gefitinib-resistant lung cancer by celastrol
}

\author{
SU-WEI XU ${ }^{1}$, BETTY YUEN KWAN LAW ${ }^{1}$, SIMON WING FAI MOK ${ }^{1}$, ELAINE LAI HAN LEUNG ${ }^{1}$, \\ XING XING FAN ${ }^{1}$, PAOLO SAUL COGHI ${ }^{1}$, WU ZENG ${ }^{1}$, CHUNG-HANG LEUNG ${ }^{2}$, \\ DIK-LUNG MA ${ }^{3}$, LIANG LIU ${ }^{1}$ and VINCENT KAM WAI WONG ${ }^{1}$ \\ ${ }^{1}$ State Key Laboratory of Quality Research in Chinese Medicine, Macau University of Science and Technology, Macau; \\ ${ }^{2}$ State Key Laboratory of Quality Research in Chinese Medicine, Institute of Chinese Medical Sciences, University \\ of Macau, Macau; ${ }^{3}$ Department of Chemistry, Hong Kong Baptist University, Hong Kong, P.R. China
}

Received May 10, 2016; Accepted June 30, 2016

DOI: $10.3892 /$ ijo.2016.3644

\begin{abstract}
Drug resistance of non-small cell lung cancer (NSCLC) is highly correlated to the mutation of the epidermal growth factor receptor (EGFR). Although EGFR tyrosine kinase inhibitors (TKIs) are available clinically, the molecular complexity of NSCLC has made it necessary to search for alternative therapeutic approaches to overcome the drug resistance of NSCLC. In the present study, we identified a triterpene molecule derived from the herbal plant Tripterygium wilfordii, celastrol, as a novel autophagy inducer. We demonstrate that celastrol exhibited selective cytotoxic effect towards EGFR mutant NSCLCs. In addition, celastrol also facilitated the autophagic degradation of Hsp90 client protein including EGFR and Akt on both EGFR wild-type and mutant NSCLCs via calcium-mediated autophagy. Blockage of celastrol-induced autophagic degradation of EGFR by autophagic inhibitor or calcium chelator decreased celastrol-mediated cell death in gefitinib-resistant NSCLCs. Overall, our findings suggest that celastrol may be developed as an effective anticancer agent for treatment of gefitinib-resistant NSCLC in the future.
\end{abstract}

\section{Introduction}

The receptor tyrosine kinase (TK), epidermal growth factor receptor (EGFR) is involved in human physiological or metabolic processes (1). Upon the binding of the endogenous ligands such as epidermal growth factor (EGF), transforming growth factor- $\alpha$ (TGF- $\alpha$ ), amphiregulin, heparin-binding EGF, or

Correspondence to: Dr Vincent Kam Wai Wong or Professor Liang Liu, State Key Laboratory of Quality Research in Chinese Medicine, Macau University of Science and Technology, Avenida Wai Long, Taipa, Macau, China

E-mail: bowaiwong@gmail.com

E-mail: 1liu@must.edu.mo

Key words: celastrol, calcium, autophagy, epidermal growth factor receptor, gefitinib-resistant lung cancer betacellulin to the EGFR, homo- or hetero-dimerization of the EGFRs occur and lead to internalization and autophosphorylation of the intracytoplasmic EGFR tyrosine kinase domains. The phosphorylated tyrosine kinase then activates several downstream signaling pathways such as the RAS-RAF-MEKERK-MAPK (RAS-MAPK), PI3K-AKT and JAK-STAT pathways, which are responsible for regulating both apoptosis and proliferation of cells (2). However, an increased gene copy number or mutation of EGFR could lead to the dysregulated activation of EGFR tyrosine kinase (TK), which finally contributes to the increased survival, proliferation, invasion and metastasis rate of tumor cells (3). In fact, more than $60 \%$ of metastatic non-small cell lung cancer (NSCLC) patients have overexpression of EGFR with poor prognosis (4).

Small molecule EGFR tyrosine kinases inhibitor (TKI) can inhibit the autophosphorylation, activation and signal transduction of EGFR. Erlotinib and gefitinib are the firstgeneration oral synthetic anilinoquinazoline TKIs that bind reversibly to the EGFR TK domain (2). New generation of EGFR TKIs such as neratinib (5), afatinib (6) and dacomitinib (7) are irreversible inhibitors of the ErbB family. EGFR mutations are commonly found in NSCLC and contribute to the early development of lung cancer (1). However, it should be noted that the sensitivity of the NSCLC to gefitinib and erlotinib is highly dependent on the type of EGFR mutations. For example, NSCLC cells with L858R mutant in EGFR are more sensitive to gefitinib than those with G719S mutant (8).

Importantly, acquired drug resistance to gefitinib and erlotinib is observed in NSCLC tumors with a point mutation in the TK domain. For example, the threonine-790 to methionine (T790M) substitution point mutation was found in approximately $50 \%$ of cancer patients with acquired resistance to EGFR TKI therapy, suggesting that T790M may work as a biomarker for identifying patients who might be resistant to erlotinib or gefitinib treatments (1). Further studies supported the presence of T790M in gefitinib-sensitive cells confers resistance to gefitinib treatment (9). Therefore, cancers with T790M or other point mutations which may contribute to drug resistant of TKIs remain as an important clinical challenge.

Autophagy is a well-known cellular maintenance mechanism responsible for the degradation of unwanted organelles 
and proteins to maintain normal cellular biosynthesis during nutrient deprivation or metabolic stressful conditions. Disruption on the autophagic function of cells can promote tumorigenesis. In fact, various studies have demonstrated autophagy as a tumor suppressor mechanism via accelerating the removal of damaged organelles and proteins to maintain normal cell growth and stability of genome (10). It was showed that mice with deficient autophagic related gene beclin 1 were more susceptible to tumor development, suggesting the tumor suppression role of autophagy (11). In fact, prolonged constitutive activation of autophagy may eventually lead to the induction of autophagic cell death, when turnover of cellular content overwhelm the capacity of the cell (9). Therefore, the induction of autophagic cell death has been an attractive anticancers therapeutic approach recently. For example, a novel small molecule (STF-62247) was demonstrated to promote autophagic cell death in renal carcinoma cells, although the role of autophagy in cancer therapy remained controversial (12).

Celastrol, a triterpene extracted from the herbal plant Tripterygium wilfordii, has been shown to induce apoptotic cell death in gefitinib-resistant non-small cell lung cancer (NSCLC) cells (H1650 and H1975) with the loss of mitochondria membrane potential, and promote degradation of two well-known client proteins of Hsp90, EGFR and AKT (13). Although the pharmacological role of celastrol has been identified in various diseases including cancers, rheumatoid arthritis, lateral sclerosis, lupus erythematosus, asthma and Alzheimer's disease, the mechanisms underlying celastrol-induced client proteins degradation remain uninvestigated (13). In the present study, we investigated the autophagic property of celastrol, and further studied the mechanisms governing the degradation of EGFR in gefitinib-resistant NSCLCs.

Our results demonstrated that celastrol induced substantial cytotoxic effect and mobilized cytosolic calcium in EGFR mutant NSCLCs. Celastrol also induced degradation of Hsp90 client protein in both wild-type and mutant EGFR NSCLCs via mobilization of calcium and autophagy. Further analysis by immuno-fluorescence staining confirmed that celastrol induced autophagy and EGFR degradation simultaneously in H1975 gefitinib-resistant NSCLCs, suggesting the anticancer properties of celastrol via promoting the degradation of EGFR through calcium-mediated autophagy induction in resistant cancer cells.

\section{Materials and methods}

Reagents, chemicals and antibodies. All chemicals and reagents were purchased from Sigma-Aldrich unless otherwise stated. The following regents were used: 3-methyladenine (189490; Calbiochem, San Diego CA, USA), BAPTA/AM (196419; Calbiochem), celastrol (China Chengdu MUST, A0106), RIPA lysis buffer (9806; Cell Signaling Technology, Danvers, MA, USA), Fluo-3, AM (F14218; Life Technologies, Carlsbad, CA, USA), antibody against LC3B (2775; Cell Signaling Technology), EGFR (5735S; Cell Signaling Technology), Akt (9272; Cell Signaling Technology), anti$\beta$-actin (sc-47778; Santa Cruz Biotechnology, Santa Cruz, CA, USA), ZyMax ${ }^{\mathrm{TM}}$ TRITC conjugated anti-mouse secondary antibody (PA1-28565; Invitrogen, Carlsbad, CA, USA). FITC conjugated anti-rabbit secondary antibody (F-2765; Invitrogen). Primer pairs for real-time PCR of EGFR: EGFR-forward, TTGCCGCAAAGTGTGTAACG and EGFR-reverse, GAG ATCGCCACTGATGGAGG.

Cell culture. All cells were obtained from the American Type Culture Collection (ATCC; Rockville, MD, USA) unless otherwise specified. All media were cultured in RPMI-1640 medium supplemented with $10 \%$ fetal bovine serum (FBS) and the antibiotics penicillin $(50 \mathrm{U} / \mathrm{ml})$ and streptomycin (50 $\mu \mathrm{g} / \mathrm{ml}$; Invitrogen, Paisley, UK). All cell cultures were incubated at $37^{\circ} \mathrm{C}$ in a $5 \%$ humidified $\mathrm{CO}_{2}$ incubator.

Cytotoxicity assays. All test compounds were dissolved in dimethyl sulfoxide (DMSO) at final concentrations of $50 \mathrm{mmol} / 1$ and stored at $-20^{\circ} \mathrm{C}$ before use. Cytotoxicity was assessed using the 3-(4,5-dimethylthiazol-2-yl)-2,5-diphenyltetrazolium bromide (MTT) $(5.0 \mathrm{mg} / \mathrm{ml})$ assay as previously described (14). Briefly, $4 \times 10^{3}$ cells were seeded/well in 96-well plates before drug treatment. After overnight culture, the cells were then exposed to different concentrations of celastrol (0.039-100 $\mu \mathrm{mol} / \mathrm{l})$ for $72 \mathrm{~h}$. Cells without drug treatment were used as control. Subsequently, MTT (10 $\mu \mathrm{l})$ was added to each well and incubated at $37^{\circ} \mathrm{C}$ for $4 \mathrm{~h}$ followed by the addition of $100 \mu \mathrm{l}$ solubilization buffer $(10 \% \mathrm{SDS}$ in $0.01 \mathrm{~mol} / \mathrm{l} \mathrm{HCl})$ and overnight incubation. $\mathrm{A}_{570} \mathrm{~nm}$ was determined from each well the next day. The percentage of cell viability was calculated using the following formula: Cell viability $(\%)=\mathrm{A}_{\text {treated }} / \mathrm{A}_{\text {control }}$ $\mathrm{x} 100$. Data were obtained from triplicate independent experiments.

Measurement of intracellular free calcium. Changes in intracellular free calcium were measured by a fluorescent dye, Fluo-3, AM as previously described (15). Briefly, NSCLC cells were washed twice with RPMI-1640 media after $2 \mu \mathrm{M}$ celastrol treatment for 0-4 h. The cell suspensions were then incubated with $5 \mu \mathrm{M}$ Fluo-3, AM at $37^{\circ} \mathrm{C}$ for $30 \mathrm{~min}$. After the cells were washed twice with HBSS, the re-suspended cell samples were then subjected to FACS analysis. At least 10,000 events were analyzed.

Endogenous LC3 and EGFR detection. The detection of endogenous LC3 was conducted using immunofluorescence staining method as described below. In brief, celastrol-treated cancer cells on coverslips were fixed with $4 \%$ paraformaldehyde (Sigma-Aldrich) for $20 \mathrm{~min}$ at room temperature and then rinsed with phosphate-buffered saline (PBS). Immerse coverslips in methanol at room temperature for $2 \mathrm{~min}$. After washing with PBS, the cells were then incubated with antiLC3 (1:200) in TBST (100 mM Tris HCl, pH 7.5, $150 \mathrm{mM}$ $\mathrm{NaCl}, 0.05 \%$ Tween-20 and 5\% BSA) overnight at $4^{\circ} \mathrm{C}$. After washing with PBS, the cells were incubated with anti-mouse secondary antibody (TRITC) 1:200 in TBST containing 5\% $\mathrm{BSA}$ at $37^{\circ} \mathrm{C}$ for $1 \mathrm{~h}$ in the dark. For detection of EGFR, the cells were incubated with anti-EGFR (1:200) in TBST (100 mM Tris $\mathrm{HCl}, \mathrm{pH} 7.5,150 \mathrm{mM} \mathrm{NaCl}, 0.05 \%$ Tween-20 and $5 \%$ BSA) overnight at $4^{\circ} \mathrm{C}$. After washing with PBS, the cells were incubated with anti-rabbit secondary antibody (FITC) 1:200 in TBST containing $5 \% \mathrm{BSA}$ at $37^{\circ} \mathrm{C}$ for $1 \mathrm{~h}$ in the dark. The coverslips were then mounted with FluorSave ${ }^{\mathrm{TM}}$ mounting 
media (Calbiochem) for fluorescence imaging and localization of LC3 autophagosomes and EGFR expression were captured under the API DeltaVision Live-cell Imaging System (Applied Precision Inc., GE Healthcare Co., Issaquah, WA, USA). To quantify autophagy, guidelines were followed to monitor autophagy (16), the percentage of cells with punctuate LC3 immunofluorescence staining was calculated by counting the number of the cells showing the increased punctuate pattern of LC3 fluorescence ( $\geq 10$ dots/cell) in immunofluorescencepositive cells over the total number of cells in the same field. A minimum of 1,000 cells from randomly selected fields were scored. To quantify EGFR expression, the intensity of green fluorescence FITC signal in cells was determined by API DeltaVision Live-cell Imaging System.

Annexin $V$ detection by flow cytometric analysis. Apoptosis was detected by Annexin V staining kit (BD Biosciences, San Jose, CA, USA). In brief, cells were exposed to the indicated concentrations of celastrol for $24 \mathrm{~h}$. Cells were then harvested and analyzed by flow cytometry using FITC-Annexin V and propidium iodide staining according to the manufacturer's instructions. Apoptotic cells were quantitatively counted by a flow cytometer (FACSAria III; BD Biosciences). Data acquisition and analysis were performed with the CellQuest (BD Biosciences) from triple independent experiments.

Protein extraction and western blotting. The celastrol treated cells were lysed with RIPA lysis buffer. Protein concentrations were determined using the Bio-Rad protein assay (Bio-Rad Laboratories, Inc., Hercules, CA, USA). The cell lysates of samples were subjected to electrophoresis on SDS polyacrylamide gels and transferred to Hybond enhanced chemiluminescence nitrocellulose membranes (Amersham Biosciences, Piscataway, NJ, USA), which were then blocked with $5 \%$ non-fat dry milk protein for $1 \mathrm{~h}$. Membranes were then incubated with the indicated primary antibodies overnight at $4^{\circ} \mathrm{C}$. The binding of the antibody was visualized by peroxidase-coupled secondary antibody using the ECL Western Blotting detection reagents (Invitrogen). Band intensities were quantified by using the software Image $\mathrm{J}(\mathrm{NIH}$, Bethesda, MD, USA).

Reverse transcriptase-polymerase chain reaction ( $R T-P C R)$ analysis. Total RNA was extracted from the cultured cancer cells using FavorPrep ${ }^{\mathrm{TM}}$ Total RNA Purification Mini kit (Favorgen Biotech Corp., Pingtung, Taiwan). The synthesis of the first strand of cDNA was followed based on the instruction of SuperScript ${ }^{\circledR}$ VILO $^{\text {TM }}$ Master Mix kit (Invitrogen, Grand Island, NY, USA). DNase-treated total RNA ( $1 \mu \mathrm{g})$ from cells was used for cDNA synthesis. Each RNA sample was incubated with the $2 \mu \mathrm{l}$ random primers and $1 \mu \mathrm{l}$ Oligo(dT) primer provided by the kit at $65^{\circ} \mathrm{C}$ for $10 \mathrm{~min}$, and then cooled on ice for $2 \mathrm{~min}$. Reaction mixture which contains reaction buffer, RNase inhibitor and reverse transcriptase was added to the tube and then incubated at $25^{\circ} \mathrm{C}$ for $10 \mathrm{~min}$ and $55^{\circ} \mathrm{C}$ for $30 \mathrm{~min}$. The reaction was terminated by heating at $70^{\circ} \mathrm{C}$ for $15 \mathrm{~min}$. Quantitative real-time PCR were carried out on ViiA ${ }^{\mathrm{TM}} 7$ real-time PCR system (Applied Biosytems, Grand Island, NY, USA) using the FastStart Universal SYBR-Green Master Rox (Roche Diagnostics, Indianapolis, IN, USA) according to the manufacturer's instructions. The PCR mixture is comprised of $10 \mu \mathrm{l}$ SYBR Master Mix, $0.3 \mu \mathrm{l}$ forward and reverse primers,

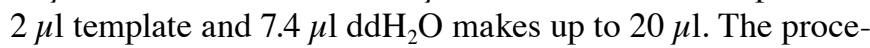
dure of RCR is $50^{\circ} \mathrm{C}$ for $2 \mathrm{~min}, 95^{\circ} \mathrm{C}$ for $10 \mathrm{~min}$, followed by 45 cycles of $95^{\circ} \mathrm{C}$ for $15 \mathrm{sec}, 60^{\circ} \mathrm{C}$ for $60 \mathrm{sec}$. Expression of each EGFR transcription level was normalized with $\beta$-actin. $\mathrm{CT}$ values were indicated in the bar charts. Ranges of values obtained in three parallel analyses were $<5 \%$ of the means.

Statistical analysis. The results were expressed as means \pm SD as indicated. The difference was considered statistically significant when the P-value was $<0.05$. Student's t-test or one-way ANOVA analysis was used for comparison among the different groups.

\section{Results}

Celastrol exhibits selective cytotoxic effect and mobilizes cytosolic calcium towards EGFR mutant NSCLCs. The natural triterpenoid compound celastrol is a promising cytotoxic agent in a great variety of cancer models (17-20). It was previously reported that celastrol has the potency to combat gefitinib-resistant NSCLCs by inducing apoptosis through caspase-dependent pathways and Hsp90 client protein degradation. However, its underlying mechanisms are still rudimentary.

To investigate the detail mechanisms of the anticancer effect of celastrol on gefitinib-resistant non-small cell lung carcinoma (NSCLC) $(17,21)$, we examined the specific cytotoxicity of celastrol (Fig. 1A) towards four NSCLC cell lines, including H1975, H1650, H820 and A549. Among these four NSCLCs, H1975 harbors L858R and T790M double mutation on EGFR, while H1650 possesses the in-frame mutation in exon 19, delE746-A750, H820 harbors exon 19 in-frame deletion and T790M double mutation on EGFR, while only A549 contains wild-type EGFR. As shown in Fig. 1B, celastrol displayed considerable more cytotoxicity against H1975 and H1650 NSCLC cells than the other NSCLC cell A549. The mean $\mathrm{IC}_{50}$ values were $0.65,0.54$ and $1.96 \mu \mathrm{M}$, respectively. The inhibitory effect of celastrol on A549 gefitinib-sensitive human lung cancer was relative lower implying that celastrol exhibited substantial cytotoxic effects towards gefitinib-resistant NSCLCs.

A previous study demonstrated that celastrol could induce cell death via calcium release from the endoplasmic reticulum (22). To investigate whether celastrol can mobilize cytosolic $\left[\mathrm{Ca}^{2+}\right]$ in NSCLCs, celastrol-treated H1975 and H1650 cells were stained with Fluo 3-AM for determination of cellular $\left[\mathrm{Ca}^{2+}\right]$ level change. Flow cytometric analysis showed that H1975 and H1650 cells loaded with Fluo 3-AM displayed a marked increase in fluorescence intensity upon the treatment of $2 \mu \mathrm{M}$ celastrol for $10 \mathrm{~min}$ (Fig. 1C and D) suggesting that celastrol significantly increased the cellular calcium level within a short time.

Celastrol induces cell death in gefitinib-resistant NSCLCs via calcium mobilization. As the celastrol-induced autophagy in gefitinib-resistant NSCLCs was due to calcium mobilization (Fig. 2), we further addressed whether celastrol-induced cell death is due to the increase of $\left[\mathrm{Ca}^{2+}\right]$ levels, we therefore 
A

C

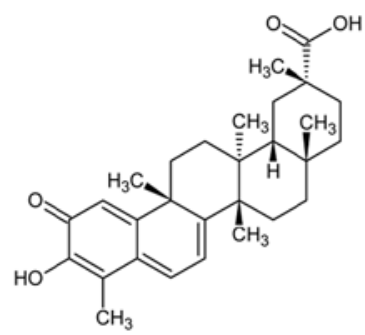

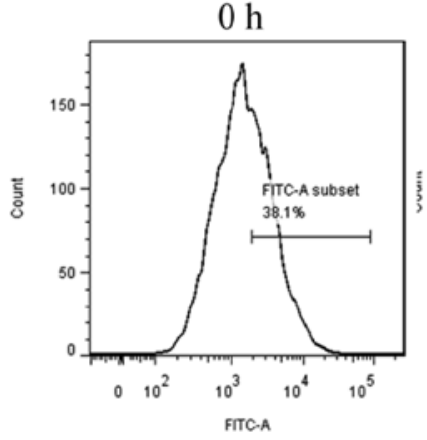

$2 \mathrm{~h}$

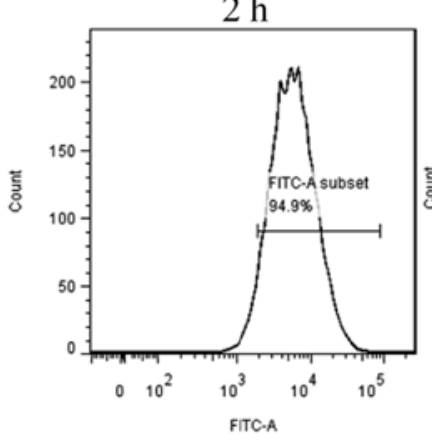

D

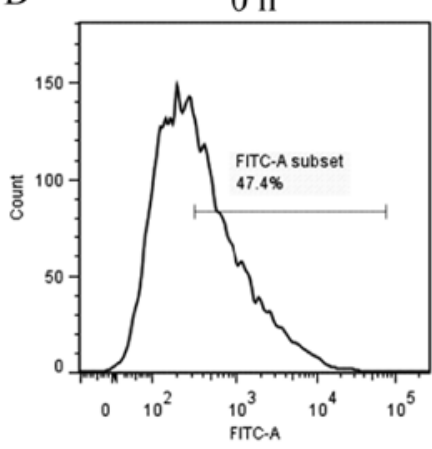

$2 \mathrm{~h}$

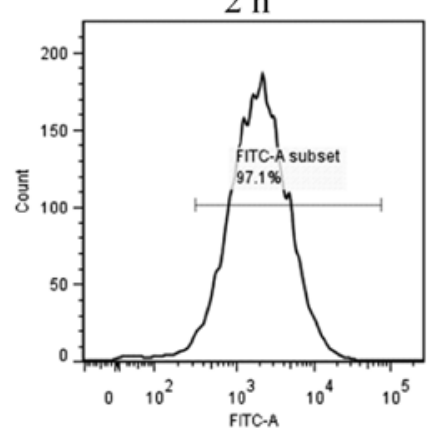

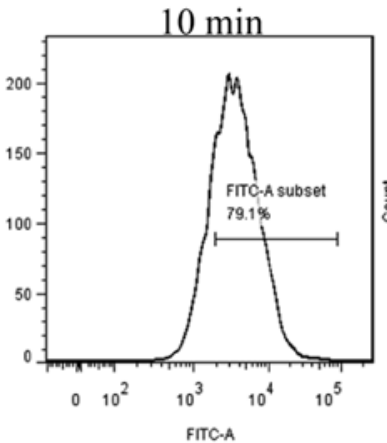

$4 \mathrm{~h}$
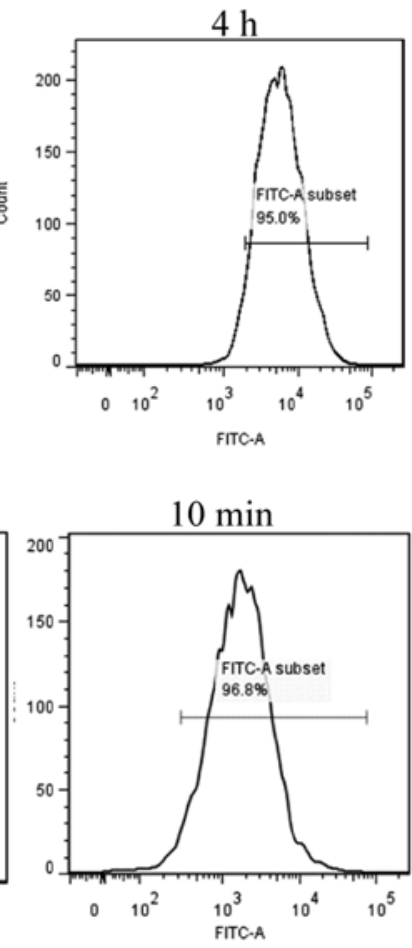

$4 \mathrm{~h}$

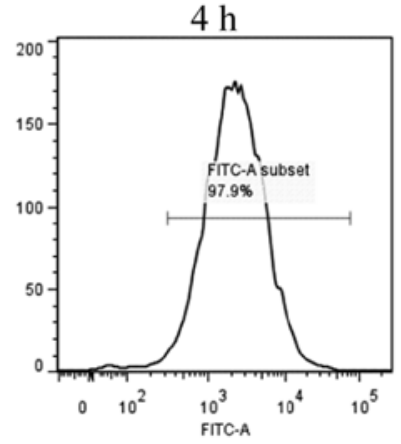

B

\begin{tabular}{|c|c|}
\hline Cell line & Means of $\mathrm{IC}_{50}[\mu \mathrm{M}]$ \\
\hline A549 (lung) & 1.96 \\
\hline $\mathrm{H} 1975$ (lung) & 0.65 \\
\hline $\mathrm{H} 1650$ (lung) & 0.54 \\
\hline $\mathrm{H} 820$ (lung) & 0.903 \\
\hline
\end{tabular}
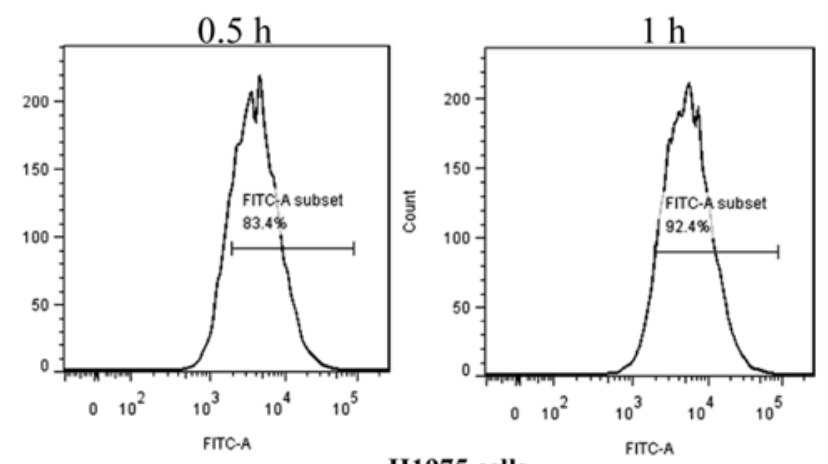

H1975 cells
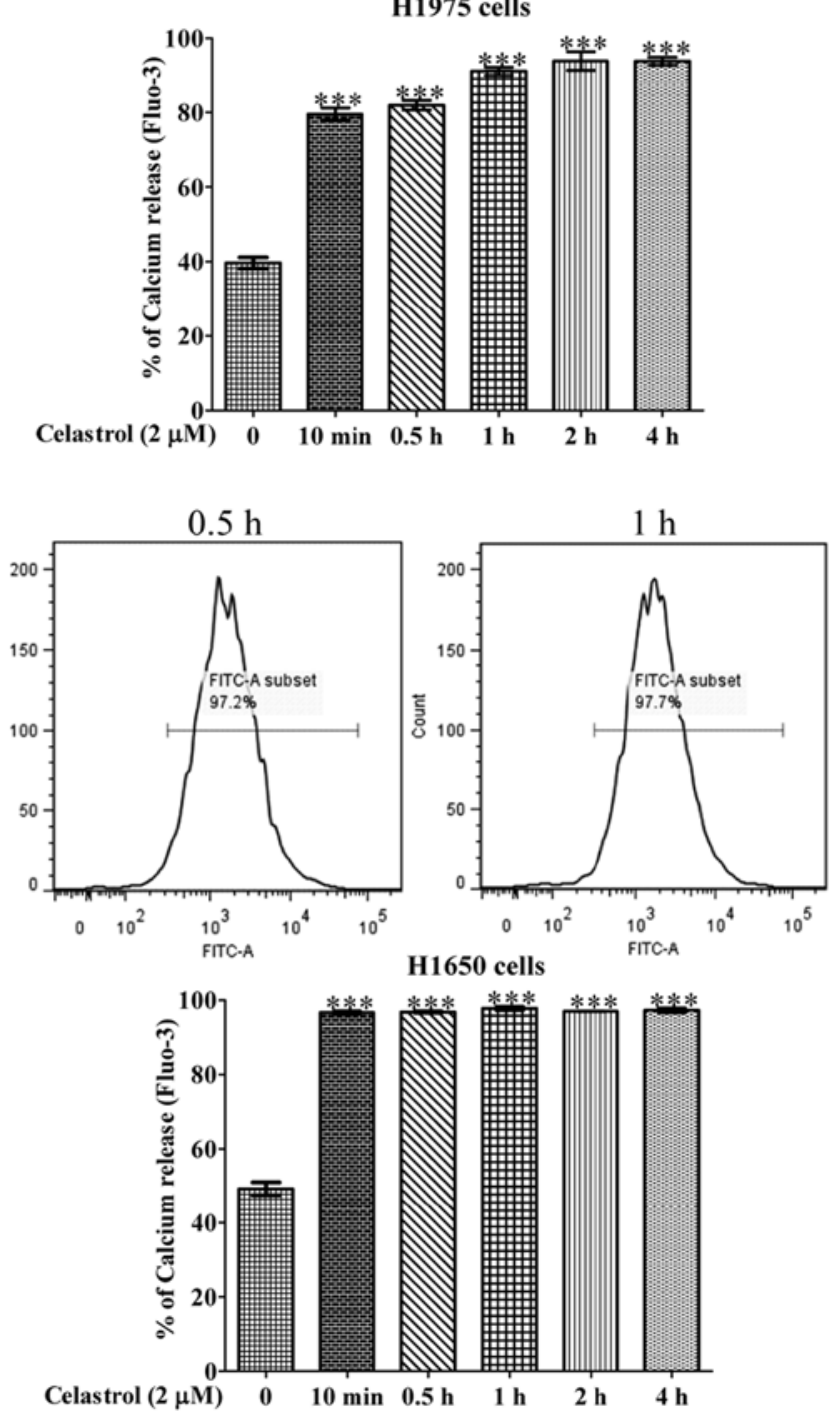

Figure 1. Celastrol increases cytotoxicity and cytosolic calcium level in gefitinib-resistant NSCLC cell lines. (A) Chemical structure of celastrol. (B) Celastrol exhibited specific cell cytotoxicity towards gefitinib-resistant NSCLC. The IC $_{50}$ values shown in the table are mean values of three independent experiments of celastrol on gefitinib-resistant NSCLC H1650, H1975 and H820 cells, when compared with A549 which contain wild-type EGFR. (C and D) Celastrol mobilized cytosolic calcium level in gefitinib-resistant NSCLC H1975 and H1650 cells. Both H1975 and H1650 cells treated with DMSO or $2 \mu \mathrm{M}$ celastrol for $10 \mathrm{~min}$ to $4 \mathrm{~h}$ were subjected to flow cytometric analysis using $5 \mu \mathrm{M}$ Fluo-3, AM dye. Intracellular Ca ${ }^{2+}$ level was determined in terms of the fluorescent activity of Fluo-3, AM by flow cytometric analysis. Data in the bar chart are the mean values \pm SD of three independent experiments; error bars, $\mathrm{SD} .{ }^{* * * *} \mathrm{P}<0.001$. 
A H1975 cells
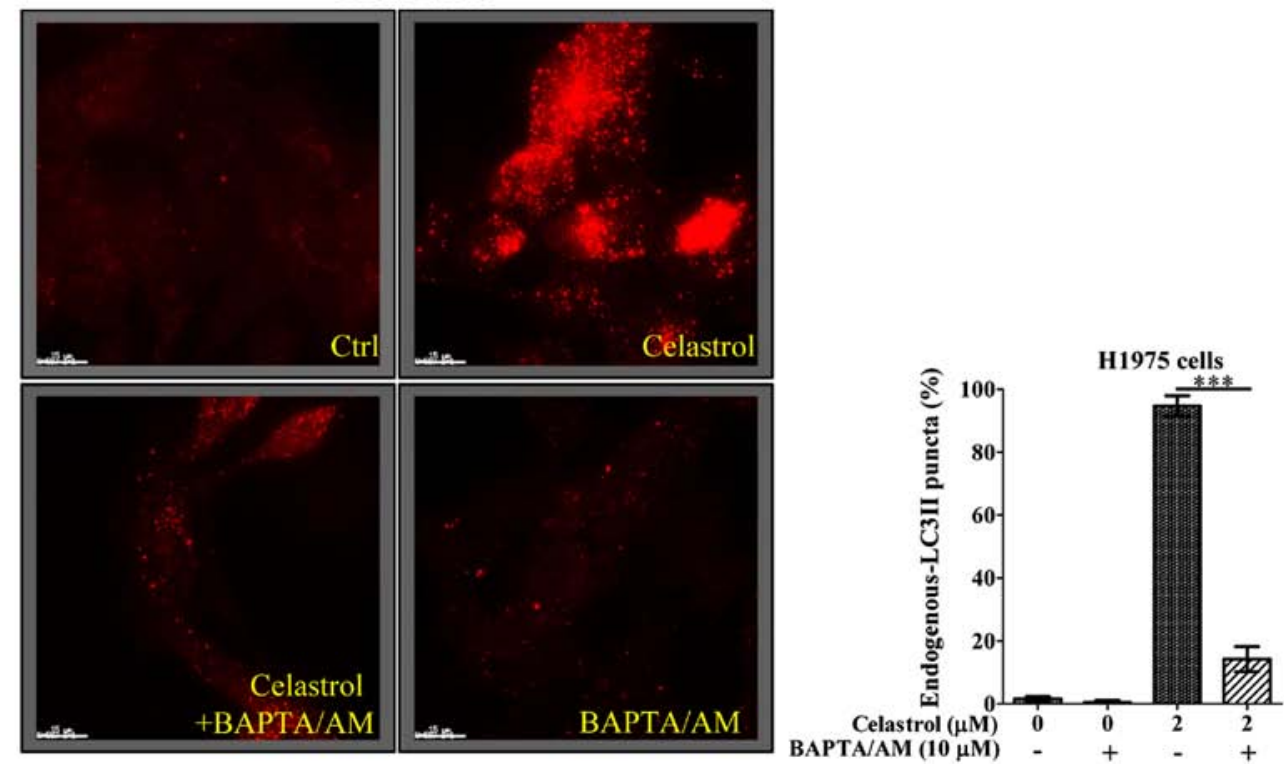

B
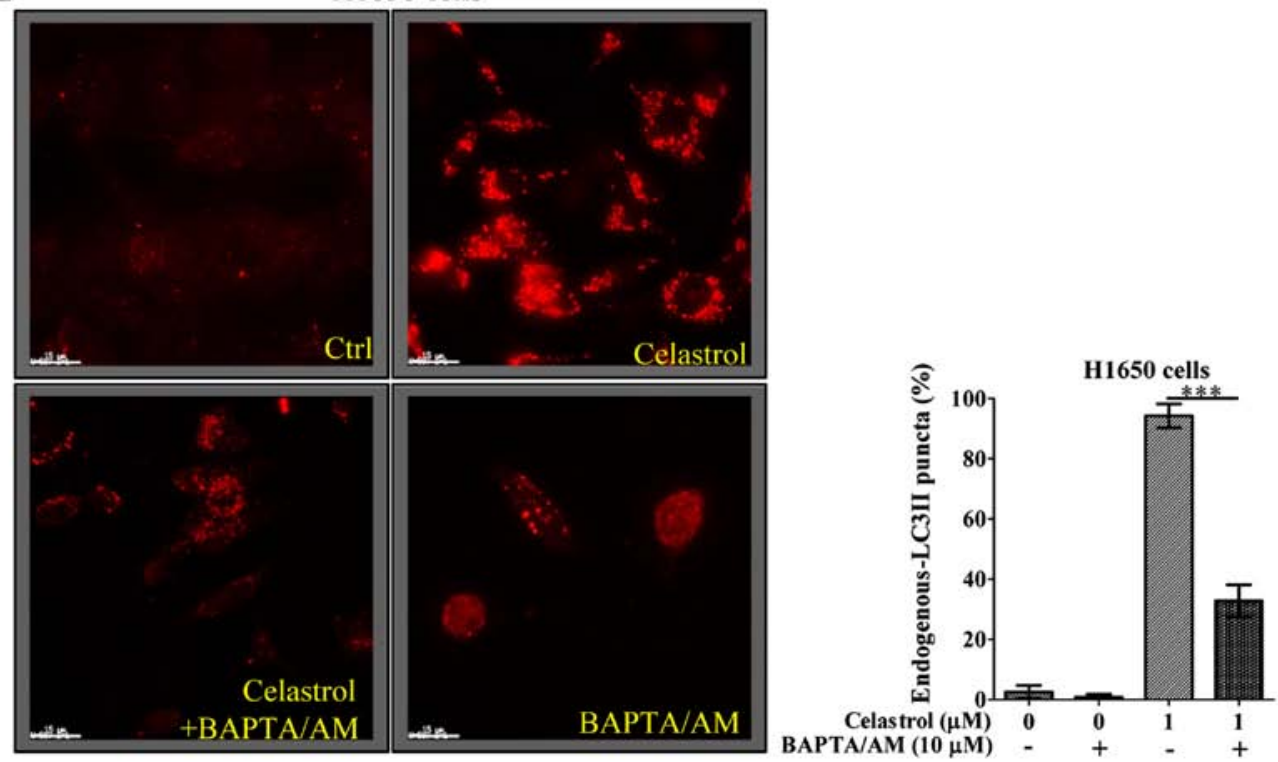

Figure 2. Celastrol induces autophagy via calcium mobilization in gefitinib-resistant NSCLC cells. (A and B) Calcium chelator BAPTA/AM abolished celastrol-induced autophagic effect in gefitinib-resistant NSCLC H1975 and H1650 cells. H1975 cells were treated with DMSO or $2 \mu$ M celastrol, while H1650 cells were treated with DMSO or $1 \mu \mathrm{M}$ celastrol for $24 \mathrm{~h}$ in the presence or absence of $10 \mu \mathrm{M}$ calcium chelator BAPTA/AM. The cells were then fixed and visualized for endogenous LC3-II expression by fluorescence microscopy using LC3-II antibody plus TRITC-conjugated anti-mouse secondary antibody. Bar charts indicated the quantitation of cells with increased autophagic puncta formation. Fluorescence images were captured at x60 magnification; scale bar, $15 \mu \mathrm{m}$. Data are mean values of three independent experiments; error bars, SD. ${ }^{* * *} \mathrm{P}<0.001$.

examined its cytotoxicity with the intracellular $\mathrm{Ca}^{2+}$ chelator (BAPTA/AM) using Annexin V flow cytometry. As shown in Fig. 3, while celastrol significantly induced cell death to $>40 \%$ in H1975 and H1650 cancer cells, addition of BAPTA/AM mostly recovered the celastrol-induced cell death. These results suggested that the increase of $\left[\mathrm{Ca}^{2+}\right]$ level and its mediated autophagy were required for celastrol-induced apoptosis.

Celastrol induces Hsp90 client protein degradation in both EGFR wild-type and mutant NSCLCs via calcium mobilization and autophagy induction. Gefitinib is a TKI of EGFR, it can specifically block the activation of EGFR by binding to its ATP binding pocket, resulting in EGFR kinase inhibition (24) and the downstream kinases like Akt which hinder cancer cell growth and survival.

Various EGFR mutants have been found existing amongst NSCLCs. Celastrol demonstrated marked inhibitory effect on both EGFR wild-type and mutant NSCLC cells. Therefore, we investigated whether this inhibitory effect on NSCLCs is due to the degradation of EGFR. As shown in Fig. 4A, celastrol potently promoted the degradation of mutant EGFR in H1975 cells. Moreover, the downstream targets of EGFR, Akt, were also inhibited with concomitant increase of autophagic LC3-II conversion. To determine whether the degradation of EGFR is mutant-specific, we examined the degradation of wild-type EGFR from A549 cells. As shown in Fig. 4B, the wild-type 
A

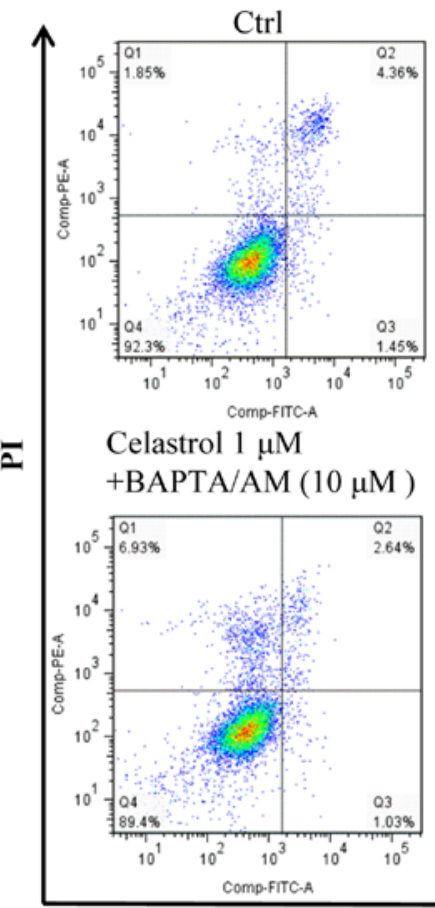

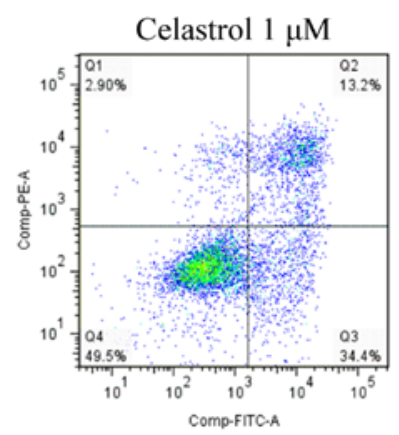

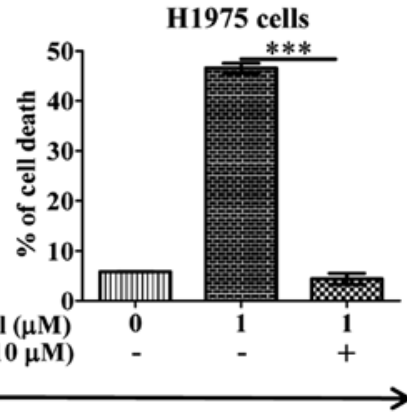

Annexin V

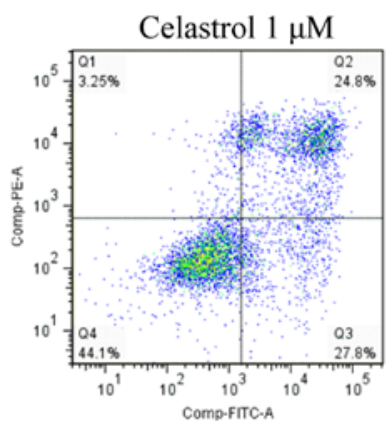

H1650 cells

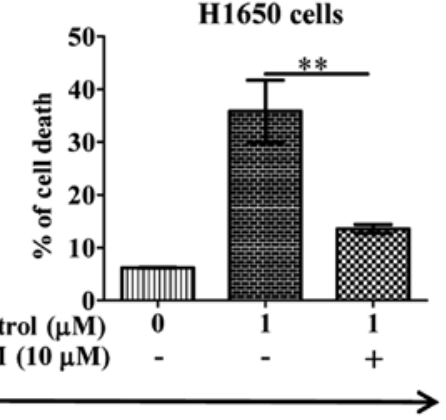

Annexin V

Figure 3. Celastrol induces apoptosis in gefitinib-resistant NSCLC cells via calcium mobilization. (A and B) Calcium chelator, BAPTA/AM abrogated the celastrol-induced cell death in gefitinib-resistant NSCLC cells. H1975 or H1650 cells were incubated with DMSO (Ctrl) or $1 \mu$ M celastrol in the presence or absence of $10 \mu \mathrm{M}$ calcium chelator BAPTA/AM, respectively for $24 \mathrm{~h}$. Celastrol-induced cell death was then measured by flow cytometric analysis using Annexin V staining kit. Bar chart data are the mean values \pm SD of early apoptosis $(\mathrm{Q} 3)$ and late apoptosis $(\mathrm{Q} 2)$ from three independent experiments; error bars, SD. ${ }^{* * *} \mathrm{P}<0.001,{ }^{* * *} \mathrm{P}<0.01$.

EGFR was significantly degraded in A549 lung cancer cells, suggesting there was no selectivity on celastrol-induced EGFR degradation in NSCLCs.

To verify whether the celastrol stimulated degradation of EGFR through cytosolic calcium mobilization and autophagy induction, we employed BAPTA/AM and 3-MA to co-incubate with celastrol on both H1975 and A549 cells. BAPTA/ AM and 3-MA markedly prevented the celastrol-mediated degradation of either wild-type or mutant EGFR, and abolished the celastrol-suppressed Akt expression in both H1975 and A549 NSCLCs, revealing that the inhibition on EGFR activation by celastrol benefit from calcium mobilization and autophagy induction. As expected, BAPTA/AM or 3-MA was able to suppress celastrol-induced LC3-II conversion in H1975 and A549 (Fig. 4). Taken together, celastrol was able to significantly suppress the activity of wild-type and mutant 
A

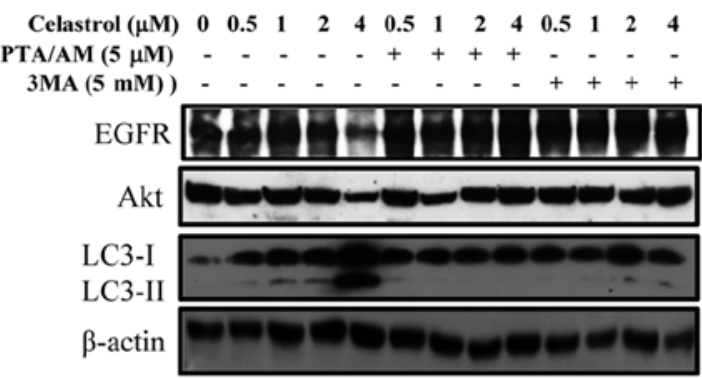

EGFR

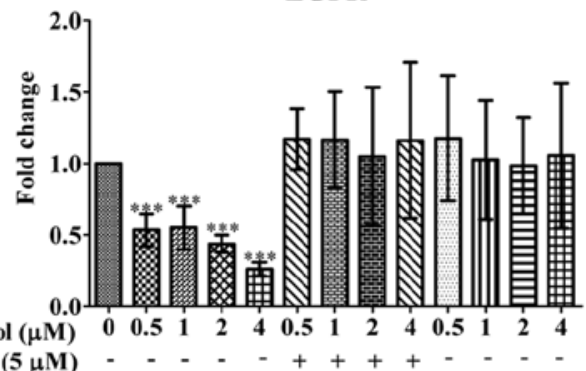

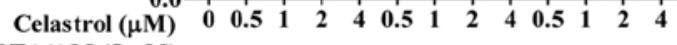

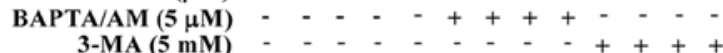

3-MA $(5 \mathrm{mM})$

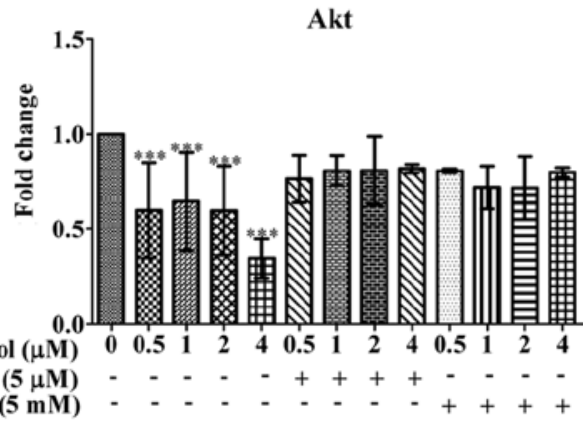

LC3

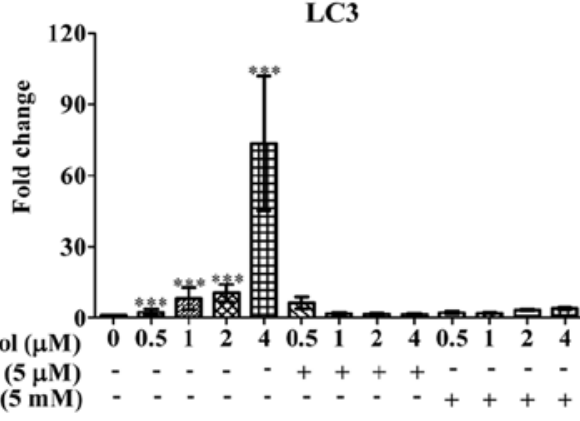

B

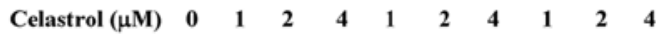

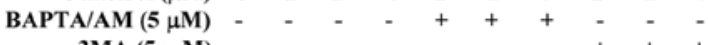

3MA (5 mM)
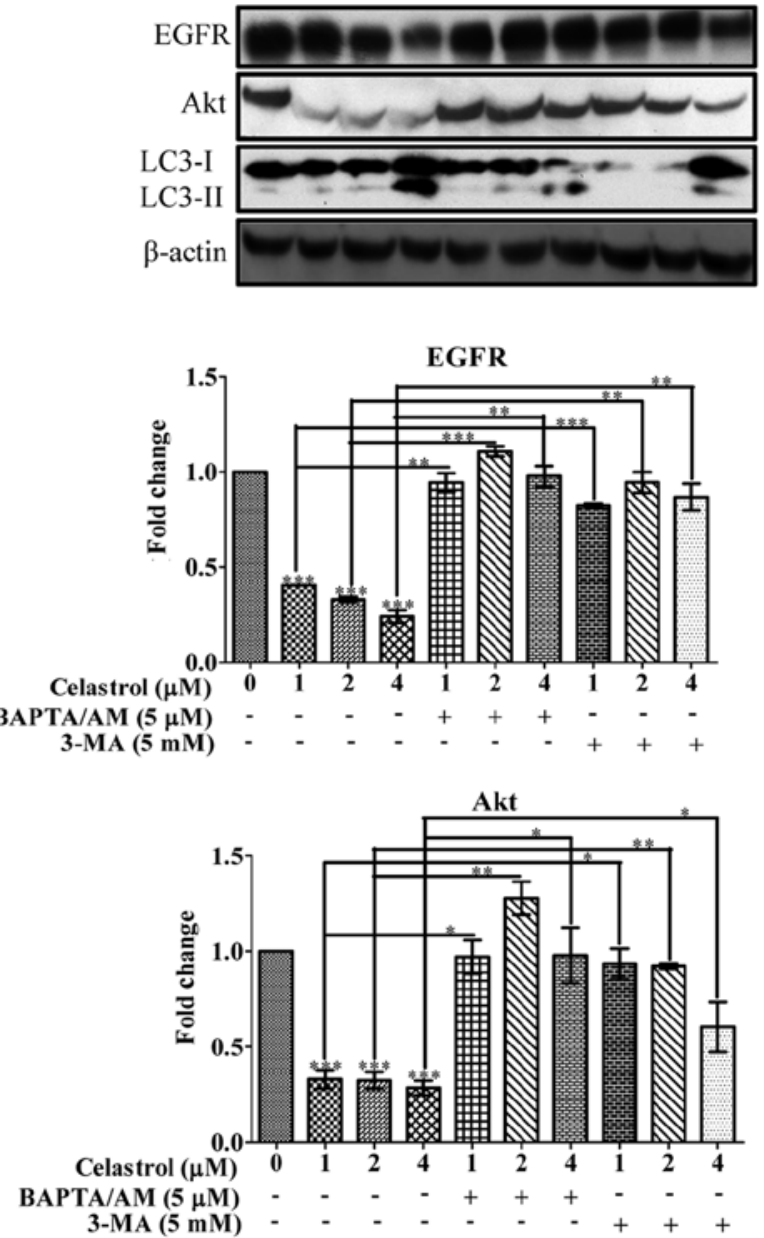

CeAs/AM $(5 \mu \mathrm{M})$

3-MA (5 m M)

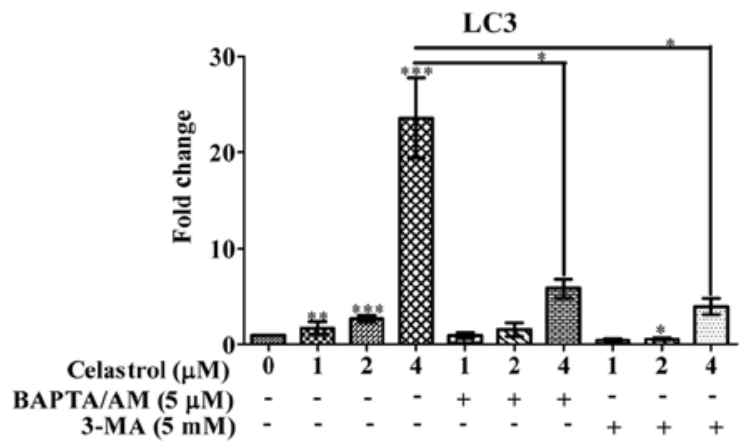

Figure 4. Celastrol induces Hsp90 client protein degradation in both EGFR wild-type and mutant NSCLCs via calcium mobilization and autophagy induction. (A and B) Both calcium chelator BAPTA/AM and autophagic inhibitor 3-MA suppressed celastrol-mediated degradation of Hsp90 client proteins: EGFR and Akt, as well as LC3-II conversion on EGFR wild-type and mutant NSCLCs. EGFR mutant H1975 cells were treated with DMSO or 0.5, 1,2 and $4 \mu$ M of celastrol, whereas EGFR wild-type A549 cells were treated with DMSO or 1,2 and $4 \mu \mathrm{M}$ of celastrol for $24 \mathrm{~h}$ in the presence or absence of $5 \mu \mathrm{M}$ BAPTA/AM or $5 \mathrm{mM} 3-\mathrm{MA}$, respectively. Cell lysates were then harvested and analyzed by western blot detection of EGFR, AKT and LC3 conversion (LC3-I, 18 kDa; LC3-II, $16 \mathrm{kDa}$ ) and $\beta$-actin. Protein band intensities were quantified using densitometry analysis and normalized to $\beta$-actin. Data were expressed as a fold change relative to the DMSO-treated control. Bar chart represents data of three independent experiments. Error bars, $\mathrm{SD}$. ${ }^{* * *} \mathrm{P}<0.001$.

EGFR and Akt which is necessary for the survival and growth of NSCLCs via calcium-mediated autophagy induction.

Immunofluorescence staining demonstrates that celastrol simultaneously induces autophagy and EGFR degradation in H1975 in dose-dependent manner. We further monitored the consequences of celastrol-induced autophagic activity in EGFR degradation of H1975 NSCLCs using fluorescence microscopy. As shown in Fig. 5A, while the red puncta formation (red TRITC signal) represented the endogenous LC3-II conversion conferred by celastrol-induced autophagic activity, merged images with green fluorescent image (green FITC signal) denoted as EGFR expression indicated autophagic activity of celastrol was highly associated with 
A

H1975 cells
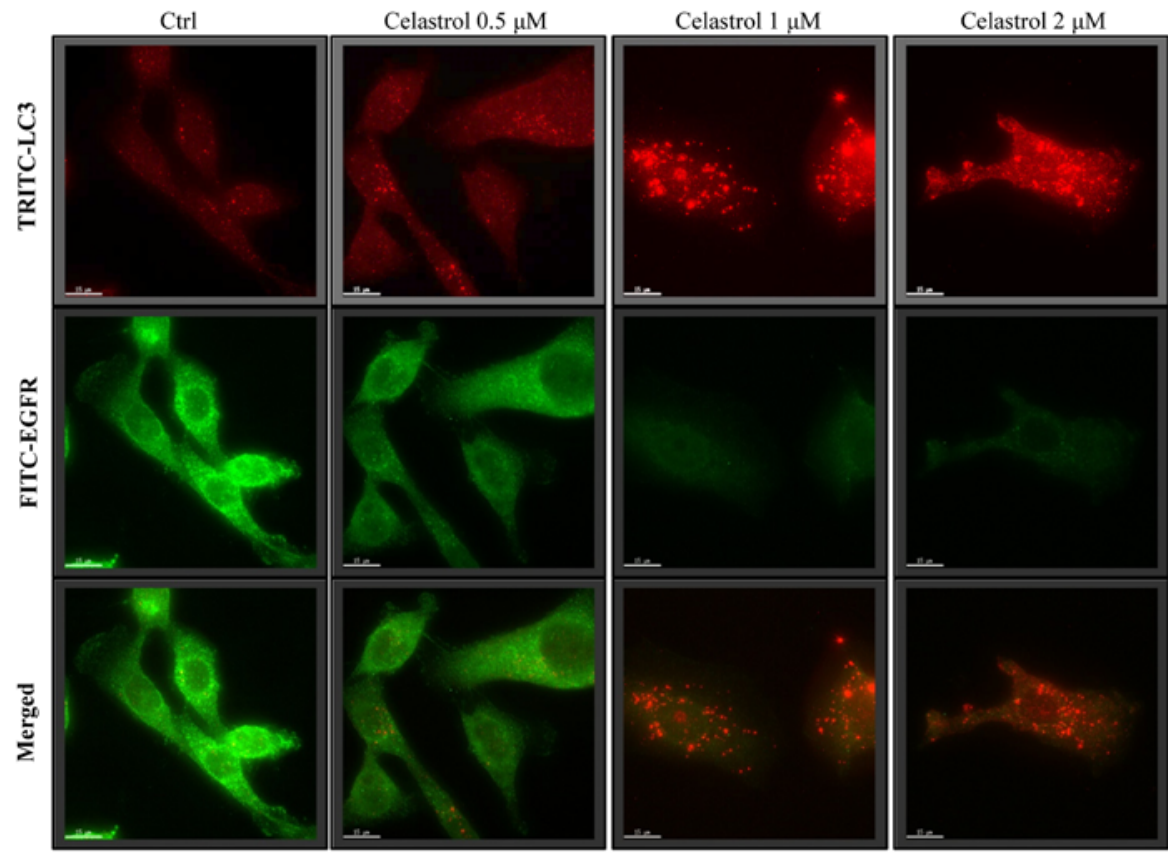

B
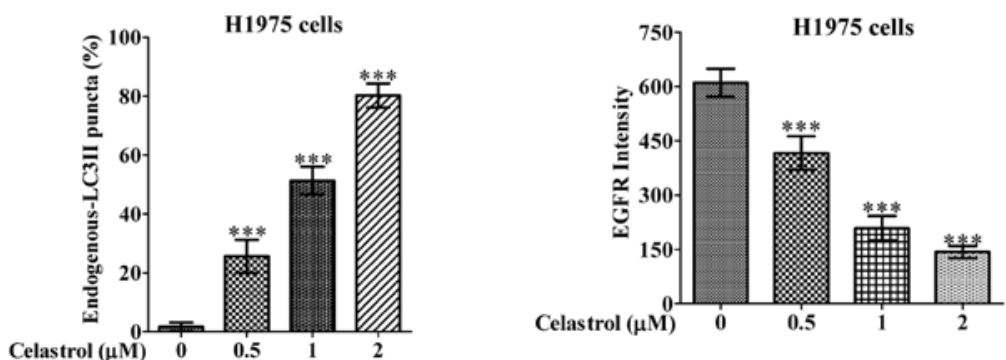

C
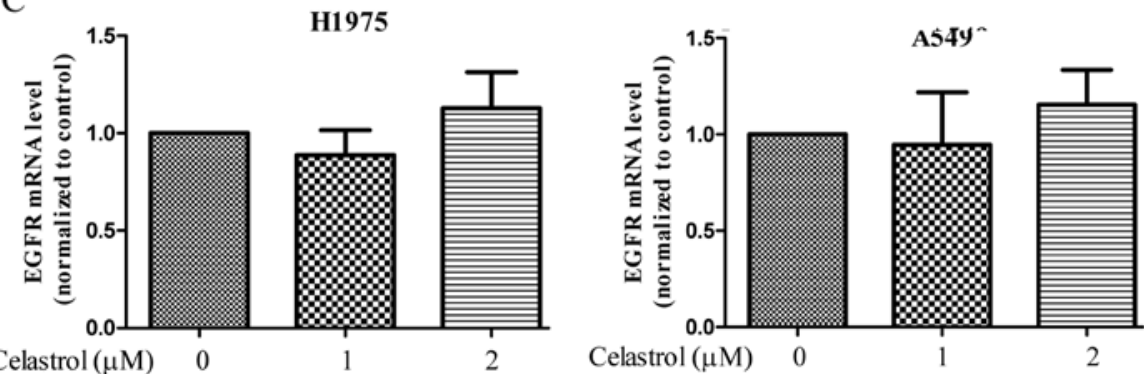

Figure 5. Degradation of EGFR is directly proportional to celastrol-induced autophagy in H1975 NSCLCs. (A) H1975 cells were treated with DMSO or $0.5-2 \mu \mathrm{M}$ of celastrol for $24 \mathrm{~h}$. Endogenous LC3 puncta (red) formation was visualized by fluorescence microscopy after staining with LC3-II antibody followed by TRITC-conjugated anti-mouse secondary antibody, whereas EGFR was visualized by staining with EGFR antibody followed by FITC-conjugated anti-rabbit secondary antibody. FITC-EGFR (green) signal intensity and TRITC-LC3 (red) puncta were scored and quantified using ImageJ software. (B) Bar charts indicated the quantitation of cells with increased autophagic puncta and EGFR green fluorescence intensity. Fluorescence images were captured at x60 magnification; scale bar, $15 \mu \mathrm{m}$. (C) Real-time PCR study of EGFR transcription level in celastol-treated H1975 and A549 cells. Data are mean values of three independent experiments; error bars, $\mathrm{SD} .{ }^{* * *} \mathrm{P}<0.001$.

the EGFR degradation. Our results demonstrated a dosedependent increase in the percentage of cells with endogenous LC3-II puncta formation (red TRITC signal) after celastrol treatment, simultaneously accompanied a dose-dependent decrease of fluorescence intensity of EGFR signal (Fig. 5B). In addition, real-time PCR revealed the unchanged EGFR transcription in both wild-type and mutant EGFR NSCLCs upon celastrol treatment (Fig. 5C), confirming that the celastrol-induced autophagy in H1975 cells may contribute to EGFR degradation.
Celastrol induces the degradation of EGFR via calciummediated autophagy induction. We further addressed how calcium mobilization and its mediated autophagic activity would eventually contribute to EGFR degradation in H1975 NSCLCs using fluorescence microscopy. As shown in Fig. 6A, while $2 \mu \mathrm{M}$ of celastrol induced vigorous autophagic effect in H1975 cancer cells reflected by red TRITC endogenous LC3-II puncta formation signal, the corresponding green fluorescent image (green FITC signal) embodied in the same cell region had immensely faded. In contrast, addition of the $\mathrm{Ca}^{2+}$ chelator 
A

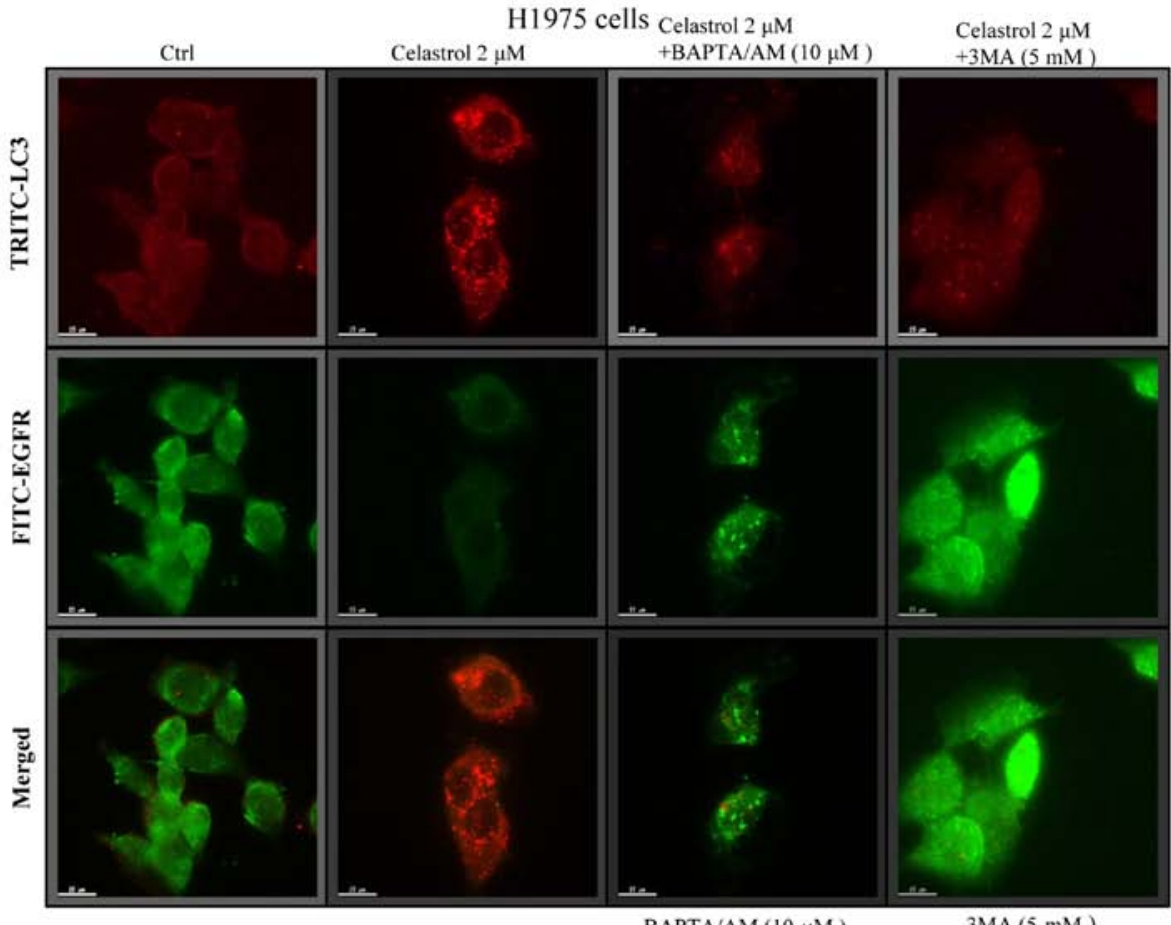

B
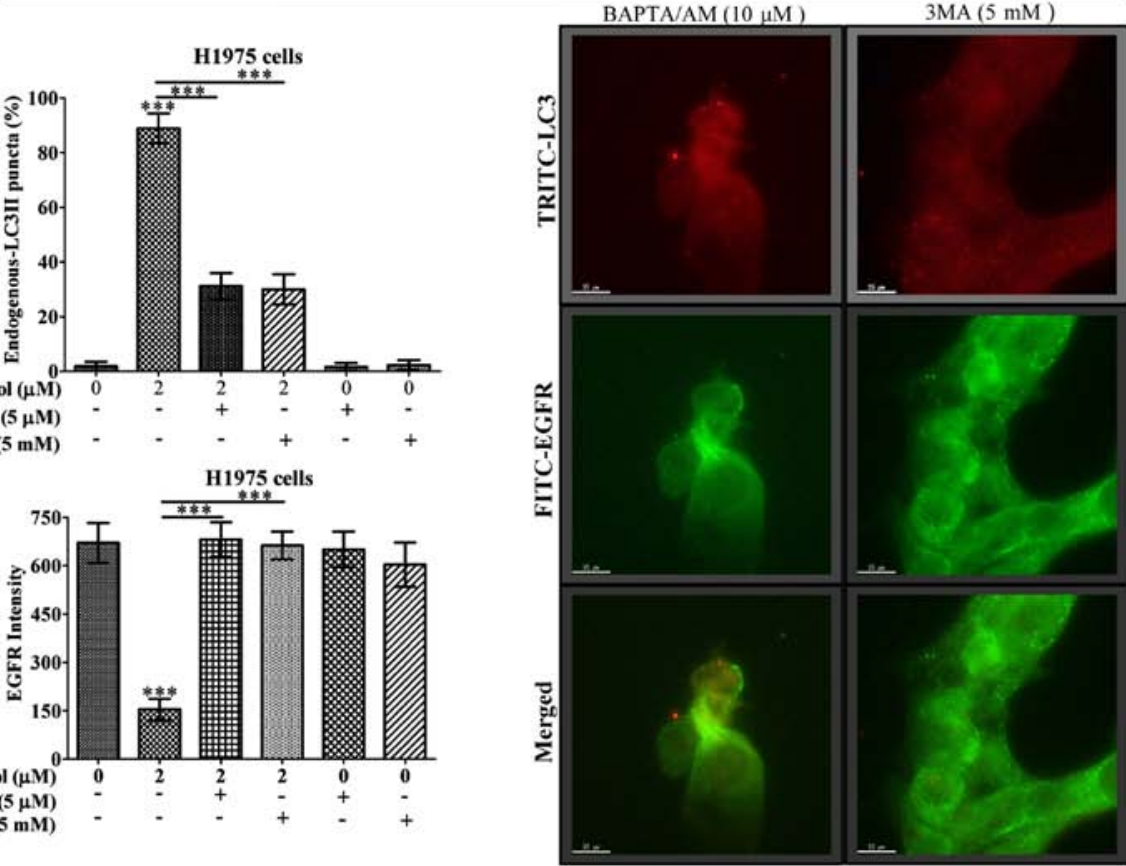

Figure 6. Celastrol induces the degradation of EGFR via calcium-mediated autophagy induction. (A) H1975 cells were treated with DMSO and $2 \mu$ M celastrol for $24 \mathrm{~h}$ in the presence or absence of $10 \mu \mathrm{M}$ calcium chelator BAPTA/AM or $5 \mathrm{mM}$ of autophagic inhibitor 3-MA. Endogenous LC3 puncta (red) formation was visualized by fluorescence microscopy after staining with LC3-II antibody followed by TRITC-conjugated anti-mouse secondary antibody, whereas EGFR was visualized by staining with EGFR antibody followed by FITC-conjugated anti-rabbit secondary antibody. FITC-EGFR (green) signal intensity and TRITC-LC3 (red) puncta were scored and quantified using ImageJ software. (B) Bar charts indicated the quantitation of cells with increased autophagic puncta and EGFR green fluorescence intensity. Fluorescence images were captured at x60 magnification; scale bar, $15 \mu \mathrm{m}$. Data are mean values of three independent experiments; error bars, $\mathrm{SD} .{ }^{* * *} \mathrm{P}<0.001$.

(BAPTA/AM) and the autophagic inhibitor 3-methyladenine (3-MA) fully recovered the celastrol-induced EGFR depletion, as well as abolished the compound-induced autophagy activity (Fig. 6B). Importantly, blockage of celastrol-induced autophagy and its mediated EGFR degradation by 3-MA would eventually increase the survival rate of $\mathrm{H} 1975$ and $\mathrm{H} 1650$ cancer cells (Fig. 7). The above evidence suggested that celastrol activates cytosolic $\left[\mathrm{Ca}^{2+}\right]$ mobilization to induce autophagy, thereby promotes the EGFR degradation and circumvents the EGFRresistant phenotype in mutant EGFR NSCLCs.

\section{Discussion}

The present study demonstrated the potential of celastrol in NSCLC intervention through direct and non-selective EGFR clearance via induction of autophagy in an intracellular 
A

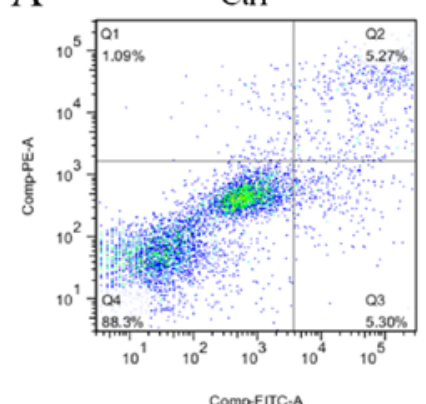

5 mM 3-MA

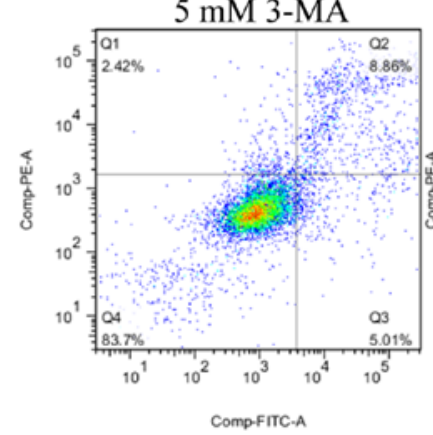

B

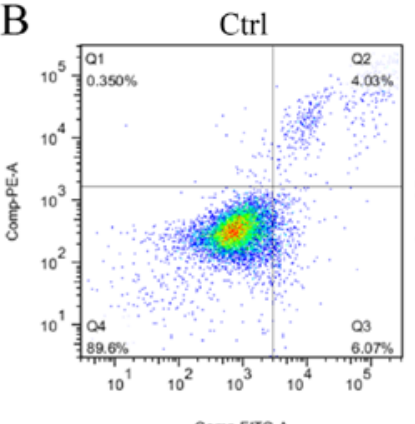

Comp-FITC-A

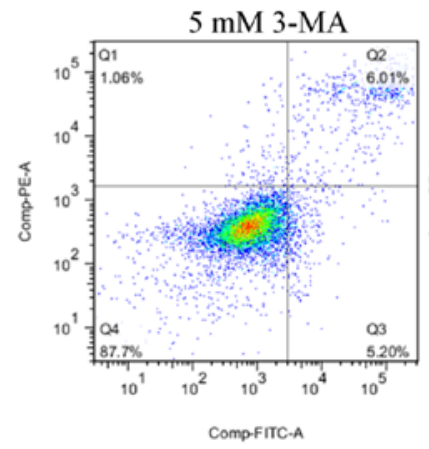

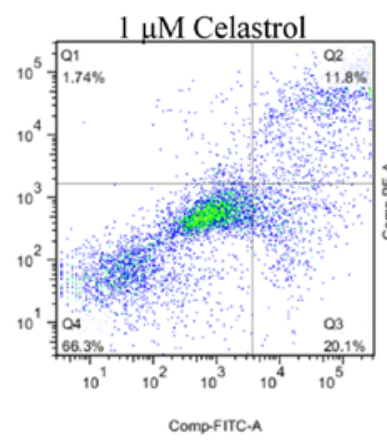

$2 \mu \mathrm{M}$ Celastrol+5 mM 3-MA

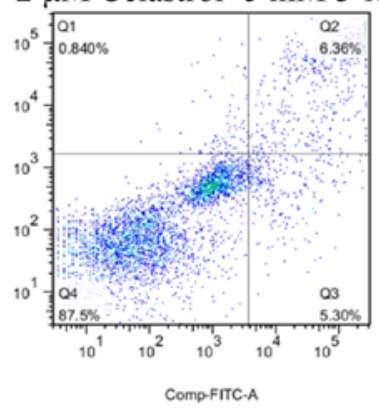

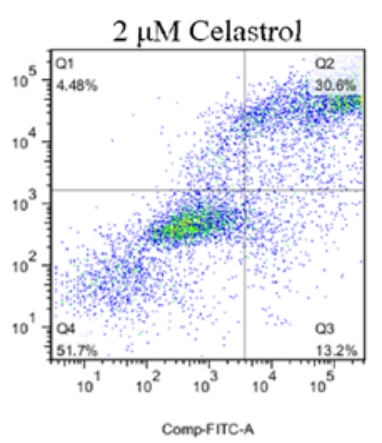

H1975

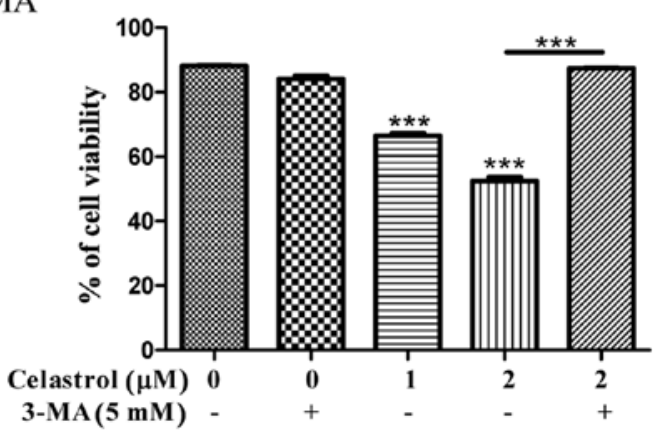

$1 \mu \mathrm{M}$ Celastrol

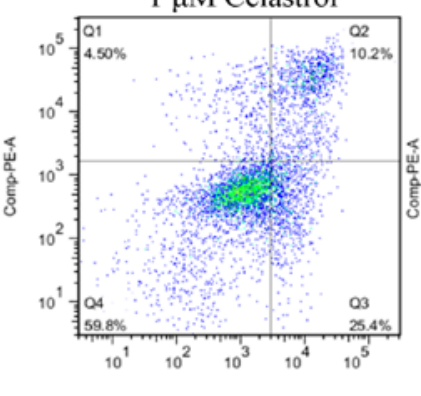

Comp.FITCA

$2 \mu \mathrm{M}$ Celastrol+5 mM 3-MA

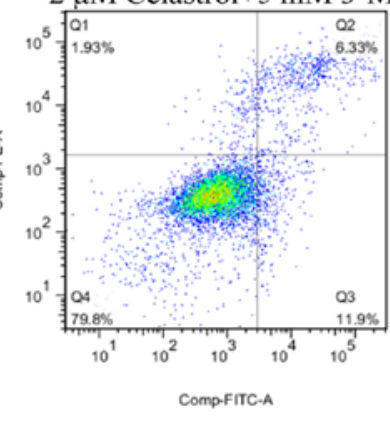

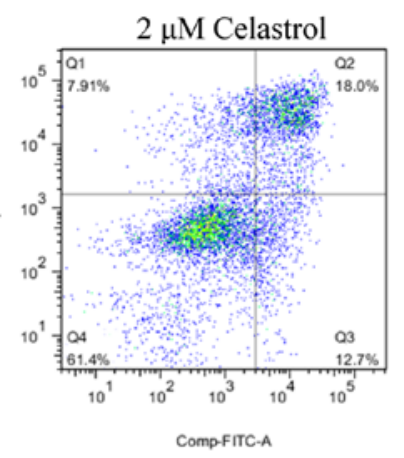

H1650

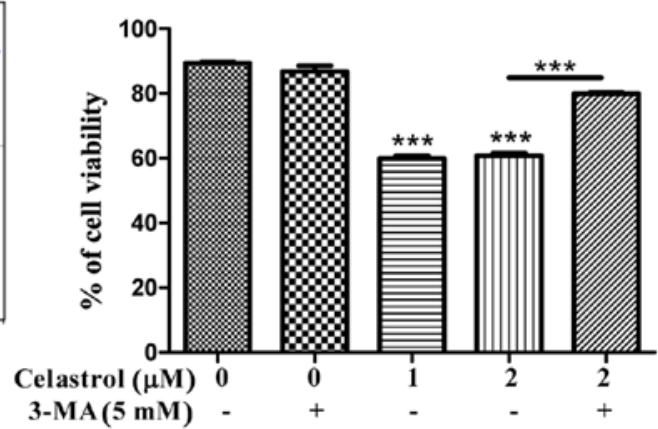

Figure 7. Autophagy inhibitor abolishes celastrol-mediated cell death in NSCLCs. (A and B) Autophagy inhibitor, 3-MA abrogated the celastrol-induced cell death in gefitinib-resistant NSCLC cells. H1975 or H1650 cells were incubated with DMSO (Ctrl) or 1-2 $\mu$ M celastrol in the presence or absence of 5 mM 3-MA, respectively for $24 \mathrm{~h}$. Celastrol-induced cell death was then measured by flow cytometric analysis using Annexin V staining kit. Bar chart represents the mean values $\pm \mathrm{SD}$ of total viable cells $(\mathrm{Q} 4)$ from three independent experiments; error bars, $\mathrm{SD}$. ${ }^{* * *} \mathrm{P}<0.001,{ }^{* *} \mathrm{P}<0.01$.

calcium-dependent manner. The cytotoxicity induced by celastrol upon our NSCLC cellular models is probably due to suppression of EGFR and downstream survival signaling after induction of EGFR loss. Since EGFR is responsible for eliciting downstream survival signaling for DNA synthesis and cell proliferation (25), therapeutic EGFR protein degradation effect induced by celastrol-mediated autophagy is likely playing the causative role in mediating apoptosis. Moreover,
EGFR loss is unlikely associated with other transcriptional manipulations, because pre-autophagy blockage significantly rescued EGFR degradation and resumed the viability of the celastrol-treated cancer cells. So et al (26) also illustrated that pharmaceutical induction of autophagy, by protein kinase CK2 (CK2) inhibitor, downregulated EGFR and led eventually to NSCLC cell death. Although CK2 inhibitor may trigger autophagy through different signaling pathways from celas- 


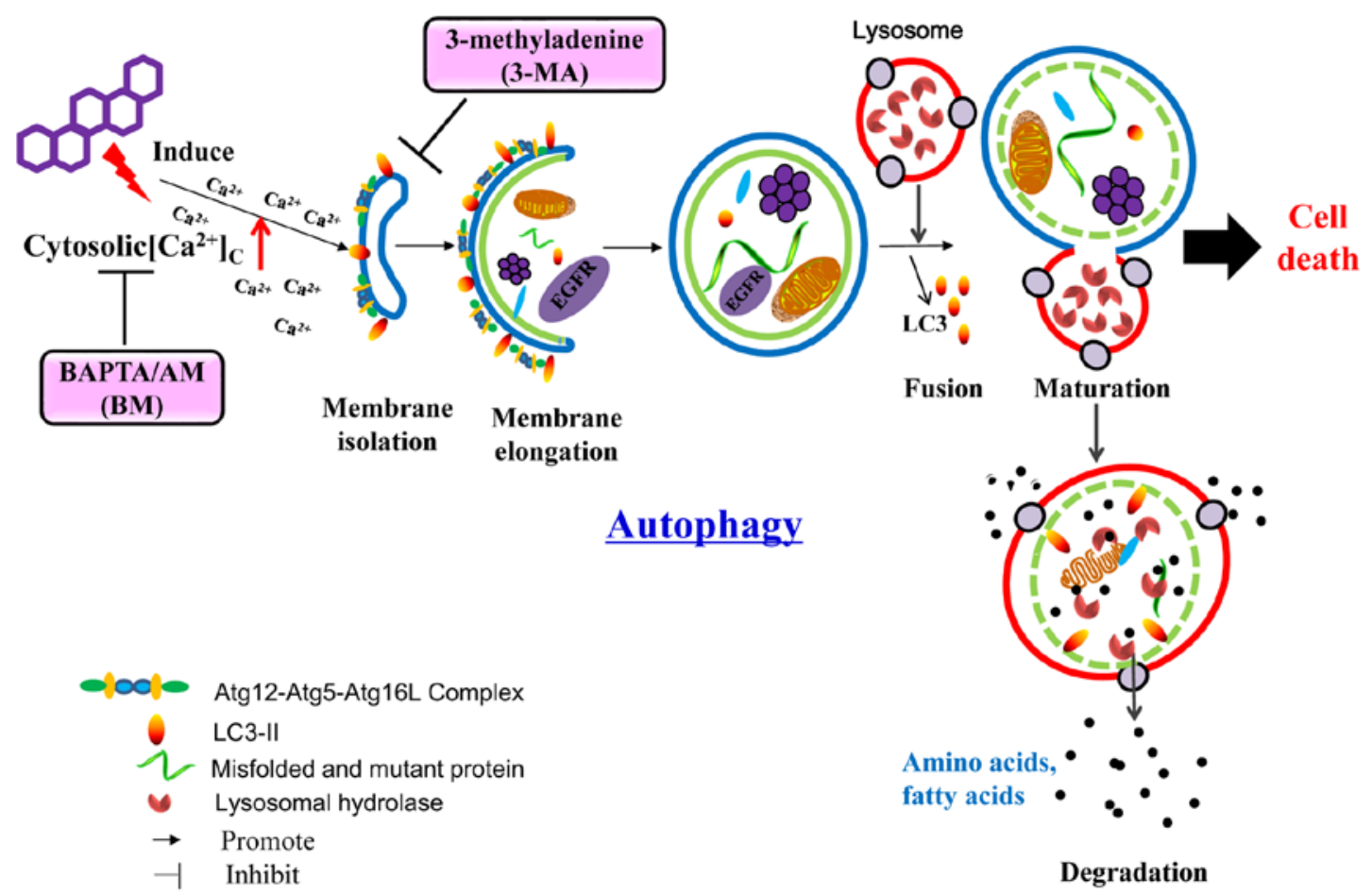

Figure 8. Schematic diagram for autophagic degradation of EGFR.

trol, at least it provides supporting evidence of the feasibility of using agent to induce direct autophagic-mediated EGFR elimination.

Almost $90 \%$ of all histological types of lung cancers belongs to NSCLC (27) [http://www.cancer.org/cancer/ lungcancer-non-smallcell/detailedguide/non-small-celllung-cancer-what-is-non-small-cell-lung-cancer] (3/11/2016), and around $60 \%$ of patients are overexpressing EGFR (27). Therefore, developing an effective intervention strategy targeting EGFR of NSCLC will greatly enhance the survival of patients. In this connection, a well-known EGFR molecular targeting strategy mainly based on the use of EGFR inhibitors have been evolved, which is the use of a small molecule TKI inhibitor. However, the clinical application of these inhibitors encountered many constraints. For example, the monocloncal antibodies cetuximab (erbitux) and panitumumab (vectibix) have been suggested as pharmaceutical intervention for NSCLC (28). These antibody inhibitors target specifically to the mutated EGFR which in turn shut down the downstream survival signaling for the cancer cells (29-32). However, the antibody-dependent cell-mediated cytotoxicity induced by the monoclonal immunoglobulin $\mathrm{G}$ proteins could be complicated (33). The use of gefitinib (Iressa) and erlotinib (Tarceva) to suppress the tyrosine kinase activities of EGFR also faced several limitations. For example, drug-resistant mutants of the cancer cells developed from compensation of parallel signaling pathways has become a major concern for maintaining the efficacy of these small molecules $(24,34)$. In addition, inhibitors which target the downstream signaling molecules, rather than EGFR per se, by manipulating their post-translational modifications, such as isoprenylation of RAS $(35,36)$, have been described. However, these signaling proteins usually compose of multiple modifications which greatly reduce the therapeutic potential of the post-translational modifiers (37). Celastrol, when compared with the above single molecules, could be a more efficient therapeutic method targeting the EGF/EGFR pathway without the mentioned practical drawbacks. In particular, the therapeutic effects of celastrol is unrelated to the genetic variations of EGFR making itself suitable for longterm treatment for cancer cells easily developed with drug resistance. Of note, celastrol is a bioactive component constituting the Chinese herbal medicine (CHM) Radix tripterygii wilfordii (38). The herb is prescribed for a variety of disorders associated with immunological dysfunctions (39), and tumorigenesis (40), implying the safety of using celastrol for further clinical development.

Expression of both EGFR and Akt were hampered after celastrol treatment. Since, nuclear EGFR is the transcription factor for Akt, it could be a result of the loss of Akt expression signaling after the treatment. However, it should not be neglected that Akt is also an oncogenic protein and can be eliminated by the celastrol-induced upregulation of autophagy. In fact, emerging studies suggest the use of autophagy inducers for promoting oncogenic protein degradation to ameliorate tumorigenesis. An autophagy-deficient animal model demonstrated that the autophagic-mediated removal of Nucleoporin p62 (p62) repressed tumor progression of hepatocellular carcinoma (HCC) (10). Although, p62 functioned as an adaptor protein assisting autophagy (41), it is a substrate of the catabolic process (41-43) and an oncogenic protein mediating the nuclear factor $-\kappa \mathrm{B}(\mathrm{NF}-\kappa \mathrm{B})$ signaling to facilitate tumorigenesis (44-46). In addition, HCC patients can be diagnosed by the expression level of alpha-1 antitrypsin protein (A1AT) in a blood sample (47). The hepatic load of its mutant, alpha1-antitrypsin Z (ATZ), is critical to the development of hepatic fibrosis which is the clinical prerequisite of HCC. The 
autophagy-inducing drug carbamazepine (CBZ) can reduce hepatic fibrosis by diminishing the accumulation of ATZ in liver (48). In the case of colon cancer, the natural flavonoid quercetin, a CHM-derived compound, that is commonly found in fruits and vegetables (49-52), exhibited similar clinical benefit. By targeting specifically to the mutated Ras protein, the use of quercetin selectively degraded the oncogenic form of Ras in colon adenocarcinoma rendering the transformation and proliferation of the cancer cells in vitro (53). The quercetininduced Ras degradation is mechanistically mediated by the proteasomal system which may imply the co-involvement of autophagy, since the two protein quality control machineries are closely inter-twined. Another in vitro treatment study for acute promyelocytic leukemia (APL) using all-trans retinoic acid and arsenic trioxide also suggested the therapeutic efficacy of autophagy-mediated oncogenic protein degradation. The oncogenic protein promyelocytic leukemia/retinoic acid receptor alpha (PML/RARA) critically underpinning the remission of APL were markedly eliminated by autophagy triggered by the two compounds (54). Gastrointestinal stromal tumors (GIST) driven by mutated KIT proto-oncogene receptor tyrosine kinase (KIT) is sensitive to autophagy enhancer treatment as well. NVP-AUY922, a heat shock protein 90 (Hsp90) inhibitor, induced specific KIT degradation through autophagy upregulation which further suppress GIST cell growth (55). All these encouraging preclinical findings, alongside our discoveries reported here, strongly suggested the therapeutic potential of autophagy-mediated oncogenic EGFR protein degradation in cancer therapy.

In conclusion, the CHM-derived celastrol represent a new pharmaceutical candidate for NSCLC intervention which acted through the direct autophagic degradation of EGFR (Fig. 8). The non-selective degradation nature of celastrol targeting both mutant and wild-type EGFR suggested that an in-depth examination, aimed to clarify the effects of celastrol on normal cell, is needed. Our findings also provided insight to the therapeutic development for other EGFR-driven cancers, such as gastric and colorectal cancers, which overcome the frequently and increasingly occurring drug-resistance problems. Most importantly, we generally depicted the possibility of managing tumorigenesis by degrading oncogenic proteins with the use of autophagy enhancers. The CHM origin of celastrol also encouraged the search of other novel autophagy enhancers from medicinal herbs, a rich source of comparatively safe natural compounds, for cancer therapy.

\section{Acknowledgements}

The present study was supported by a FDCT grant from the Macao Science and Technology Development Fund (Project code: 084/2013/A3 \& 005/2014/AMJ).

\section{References}

1. Gazdar AF: Activating and resistance mutations of EGFR in nonsmall-cell lung cancer: Role in clinical response to EGFR tyrosine kinase inhibitors. Oncogene 28 (Suppl 1): S24-S31, 2009.

2. Roengvoraphoj M, Tsongalis GJ, Dragnev KH and Rigas JR: Epidermal growth factor receptor tyrosine kinase inhibitors as initial therapy for non-small cell lung cancer: Focus on epidermal growth factor receptor mutation testing and mutation-positive patients. Cancer Treat Rev 39: 839-850, 2013.
3. Ciardiello $\mathrm{F}$ and Tortora G: EGFR antagonists in cancer treatment. N Engl J Med 358: 1160-1174, 2008.

4. Sharma SV, Bell DW, Settleman J and Haber DA: Epidermal growth factor receptor mutations in lung cancer. Nat Rev Cancer 7: 169-181, 2007.

5. Bose P and Ozer H: Neratinib: An oral, irreversible dual EGFR/ HER2 inhibitor for breast and non-small cell lung cancer. Expert Opin Investig Drugs 18: 1735-1751, 2009.

6. Li D, Ambrogio L, Shimamura T, Kubo S, Takahashi M, Chirieac LR, Padera RF, Shapiro GI, Baum A, Himmelsbach F, et al: BIBW2992, an irreversible EGFR/HER2 inhibitor highly effective in preclinical lung cancer models. Oncogene 27: 4702-4711, 2008.

7. Engelman JA, Zejnullahu K, Gale CM, Lifshits E, Gonzales AJ, Shimamura T, Zhao F, Vincent PW, Naumov GN, Bradner JE, et al: PF00299804, an irreversible pan-ERBB inhibitor, is effective in lung cancer models with EGFR and ERBB2 mutations that are resistant to gefitinib. Cancer Res 67: 11924-11932, 2007.

8. Jiang J, Greulich H, Jänne PA, Sellers WR, Meyerson M and Griffin JD: Epidermal growth factor-independent transformation of $\mathrm{Ba} / \mathrm{F} 3$ cells with cancer-derived epidermal growth factor receptor mutants induces gefitinib-sensitive cell cycle progression. Cancer Res 65: 8968-8974, 2005.

9. Greulich H, Chen TH, Feng W, Jänne PA, Alvarez JV, Zappaterra M, Bulmer SE, Frank DA, Hahn WC, Sellers WR, et al: Oncogenic transformation by inhibitor-sensitive and -resistant EGFR mutants. PLoS Med 2: e313, 2005.

10. Mathew R, Karp CM, Beaudoin B, Vuong N, Chen G, Chen HY, Bray K, Reddy A, Bhanot G, Gelinas C, et al: Autophagy suppresses tumorigenesis through elimination of p62. Cell 137: 1062-1075, 2009.

11. Qu X, Yu J, Bhagat G, Furuya N, Hibshoosh H, Troxel A, Rosen J, Eskelinen EL, Mizushima N, Ohsumi Y, et al: Promotion of tumorigenesis by heterozygous disruption of the beclin 1 autophagy gene. J Clin Invest 112: 1809-1820, 2003.

12. Turcotte S, Chan DA, Sutphin PD, Hay MP, Denny WA and Giaccia AJ: A molecule targeting VHL-deficient renal cell carcinoma that induces autophagy. Cancer Cell 14: 90-102, 2008.

13. Fan XX, Li N, Wu JL, Zhou YL, He JX, Liu L and Leung EL: Celastrol induces apoptosis in gefitinib-resistant non-small cell lung cancer cells via caspases-dependent pathways and Hsp90 client protein degradation. Molecules 19: 3508-3522, 2014.

14. Wong VKW, Zhou H, Cheung SSF, Li T and Liu L: Mechanistic study of saikosaponin-d (Ssd) on suppression of murine $\mathrm{T}$ lymphocyte activation. J Cell Biochem 107: 303-315, 2009.

15. Liu MJ, Wang Z, Ju Y, Wong RNS and Wu QY: Diosgenin induces cell cycle arrest and apoptosis in human leukemia K562 cells with the disruption of $\mathrm{Ca}^{2+}$ homeostasis. Cancer Chemother Pharmacol 55: 79-90, 2005.

16. Klionsky DJ, Abdelmohsen K, Abe A, Abedin MJ, Abeliovich $\mathrm{H}$, Acevedo Arozena A, Adachi H, Adams CM, Adams PD, Adeli K, et al: Guidelines for the use and interpretation of assays for monitoring autophagy (3rd edition). Autophagy 12: 1-222, 2016.

17. Wang WB, Feng LX, Yue QX, Wu WY, Guan SH, Jiang BH, Yang M, Liu X and Guo DA: Paraptosis accompanied by autophagy and apoptosis was induced by celastrol, a natural compound with influence on proteasome, ER stress and Hsp90. J Cell Physiol 227: 2196-2206, 2012.

18. Yang H, Chen D, Cui QC, Yuan X and Dou QP: Celastrol, a triterpene extracted from the Chinese 'Thunder of God Vine', is a potent proteasome inhibitor and suppresses human prostate cancer growth in nude mice. Cancer Res 66: 4758-4765, 2006.

19. Kannaiyan R, Shanmugam MK and Sethi G: Molecular targets of celastrol derived from Thunder of God Vine: Potential role in the treatment of inflammatory disorders and cancer. Cancer Lett 303: 9-20, 2011.

20. Boridy S, Le PU, Petrecca K and Maysinger D: Celastrol targets proteostasis and acts synergistically with a heat-shock protein 90 inhibitor to kill human glioblastoma cells. Cell Death Dis 5: e1216, 2014.

21. Deng YN, Shi J, Liu J and Qu QM: Celastrol protects human neuroblastoma SH-SY5Y cells from rotenone-induced injury through induction of autophagy. Neurochem Int 63: 1-9, 2013.

22. Yoon MJ, Lee AR, Jeong SA, Kim YS, Kim JY, Kwon YJ and Choi KS: Release of $\mathrm{Ca}^{2+}$ from the endoplasmic reticulum and its subsequent influx into mitochondria trigger celastrol-induced paraptosis in cancer cells. Oncotarget 5: 6816-6831, 2014. 
23. Li HY, Zhang J, Sun LL, Li BH, Gao HL, Xie T, Zhang N and Ye ZM: Celastrol induces apoptosis and autophagy via the ROS/ JNK signaling pathway in human osteosarcoma cells: an in vitro and in vivo study. Cell Death Dis 6: e1604, 2015.

24. Sordella R, Bell DW, Haber DA and Settleman J: Gefitinibsensitizing EGFR mutations in lung cancer activate anti-apoptotic pathways. Science 305: 1163-1167, 2004.

25. Chan LY, Kosuri S and Endy D: Refactoring bacteriophage T7. Mol Syst Biol 1: 0018, 2005.

26. So KS, Kim CH, Rho JK, Kim SY, Choi YJ, Song JS, Kim WS Choi CM, Chun YJ and Lee JC: Autophagosome-mediated EGFR down-regulation induced by the CK2 inhibitor enhances the efficacy of EGFR-TKI on EGFR-mutant lung cancer cells with resistance by T790M. PLoS One 9: e114000, 2014.

27. da Cunha Santos G, Shepherd FA and Tsao MS: EGFR mutations and lung cancer. Annu Rev Pathol 6: 49-69, 2011.

28. Pirker R and Filipits M: Cetuximab in non-small-cell lung cancer. Transl Lung Cancer Res 1: 54-60, 2012.

29. Mitsudomi T, Morita S, Yatabe Y, Negoro S, Okamoto I, Tsurutani J, Seto T, Satouchi M, Tada H, Hirashima T, et al; West Japan Oncology Group: Gefitinib versus cisplatin plus docetaxel in patients with non-small-cell lung cancer harbouring mutations of the epidermal growth factor receptor (WJTOG3405): An open label, randomised phase 3 trial. Lancet Oncol 11: 121-128, 2010.

30. Zhou C, Wu YL, Chen G, Feng J, Liu XQ, Wang C, Zhang S, Wang J, Zhou S, Ren S, et al: Erlotinib versus chemotherapy as first-line treatment for patients with advanced EGFR mutation-positive non-small-cell lung cancer (OPTIMAL, CTONG-0802): A multicentre, open-label, randomised, phase 3 study. Lancet Oncol 12: 735-742, 2011.

31. Rosell R, Carcereny E, Gervais R, Vergnenegre A, Massuti B, Felip E, Palmero R, Garcia-Gomez R, Pallares C, Sanchez JM, et al; Spanish Lung Cancer Group in collaboration with Groupe Français de Pneumo-Cancérologie and Associazione Italiana Oncologia Toracica: Erlotinib versus standard chemotherapy as first-line treatment for European patients with advanced EGFR mutation-positive non-small-cell lung cancer (EURTAC): A multicentre, open-label, randomised phase 3 trial. Lancet Oncol 13: 239-246, 2012

32. Maemondo M, Inoue A, Kobayashi K, Sugawara S, Oizumi S, Isobe $\mathrm{H}$, Gemma A, Harada M, Yoshizawa H, Kinoshita I, et al; North-East Japan Study Group: Gefitinib or chemotherapy for non-small-cell lung cancer with mutated EGFR. N Engl J Med 362: 2380-2388, 2010

33. Yan L and Beckman RA: Pharmacogenetics and pharmacogenomics in oncology therapeutic antibody development. Biotechniques 39 (S10): 565-568, 2005.

34. Pao W, Miller VA, Politi KA, Riely GJ, Somwar R, Zakowski MF Kris MG and Varmus H: Acquired resistance of lung adenocarcinomas to gefitinib or erlotinib is associated with a second mutation in the EGFR kinase domain. PLoS Med 2: e73, 2005.

35. Kohl NE, Conner MW, Gibbs JB, Graham SL, Hartman GD and Oliff A: Development of inhibitors of protein farnesylation as potential chemotherapeutic agents. J Cell Biochem Suppl 22 (S22): 145-150, 1995.

36. Ray D, Cuneo KC, Rehemtulla A, Lawrence TS and Nyati MK: Inducing oncoprotein degradation to improve targeted cancer therapy. Neoplasia 17: 697-703, 2015.

37. Vasan N, Boyer JL and Herbst RS: A RAS renaissance: Emerging targeted therapies for KRAS-mutated non-small cell lung cancer. Clin Cancer Res 20: 3921-3930, 2014.

38. Hu H, Straub A, Tian Z, Bassler N, Cheng J and Peter K: Celastrol, a triterpene extracted from Tripterygium wilfordii Hook F, inhibits platelet activation. J Cardiovasc Pharmacol 54 $240-245,2009$.
39. Tang W and Zuo JP: Immunosuppressant discovery from Tripterygium wilfordii Hook f: The novel triptolide analog (5R)-5-hydroxytriptolide (LLDT-8). Acta Pharmacol Sin 33: $1112-1118,2012$

40. Kannaiyan R, Manu KA, Chen L, Li F, Rajendran P Subramaniam A, Lam P, Kumar AP and Sethi G: Celastrol inhibits tumor cell proliferation and promotes apoptosis through the activation of c-Jun N-terminal kinase and suppression of PI3 K/Akt signaling pathways. Apoptosis 16: 1028-1041, 2011.

41. Pankiv S, Clausen TH, Lamark T, Brech A, Bruun JA, Outzen H, Øvervatn A, Bjørkøy G and Johansen T: p62/SQSTM1 binds directly to Atg8/LC3 to facilitate degradation of ubiquitinated protein aggregates by autophagy. J Biol Chem 282: 24131-24145, 2007.

42. Bjørkøy G, Lamark T, Brech A, Outzen H, Perander M, Overvatn A, Stenmark H and Johansen T: p62/SQSTM1 forms protein aggregates degraded by autophagy and has a protective effect on huntingtin-induced cell death. J Cell Biol 171: 603-614, 2005

43. Ichimura Y, Kumanomidou T, Sou YS, Mizushima T, Ezaki J, Ueno T, Kominami E, Yamane T, Tanaka K and Komatsu M: Structural basis for sorting mechanism of p62 in selective autophagy. J Biol Chem 283: 22847-22857, 2008.

44. Duran A, Linares JF, Galvez AS, Wikenheiser K, Flores JM, Diaz-Meco MT and Moscat J: The signaling adaptor p62 is an important NF-kappaB mediator in tumorigenesis. Cancer Cell 13: 343-354, 2008.

45. Komatsu M, Waguri S, Koike M, Sou YS, Ueno T, Hara T, Mizushima N, Iwata J, Ezaki J, Murata S, et al: Homeostatic levels of p62 control cytoplasmic inclusion body formation in autophagy-deficient mice. Cell 131: 1149-1163, 2007.

46. Takamura A, Komatsu M, Hara T, Sakamoto A, Kishi C, Waguri S, Eishi Y, Hino O, Tanaka K and Mizushima N: Autophagy-deficient mice develop multiple liver tumors. Genes Dev 25: 795-800, 2011.

47. Varela AS and López Sáez JJ: Utility of plasmatic levels of alpha1-antiprotease (A1AP) as a cancer marker. Cancer Lett 89: 15-21, 1995.

48. Hidvegi T, Ewing M, Hale P, Dippold C, Beckett C, Kemp C, Maurice N, Mukherjee A, Goldbach C, Watkins S, et al: An autophagy-enhancing drug promotes degradation of mutant $\alpha 1$-antitrypsin $\mathrm{Z}$ and reduces hepatic fibrosis. Science 329: 229-232, 2010.

49. Xianfei X, Xiaoqiang C, Shunying Z and Guolin Z: Chemical composition and antimicrobial activity of essential oils of Chaenomeles speciosa from China. Food Chem 100: 1312-1315, 2007.

50. Nahrstedt A and Butterweck V: Biologically active and other chemical constituents of the herb of Hypericum perforatum $\mathrm{L}$. Pharmacopsychiatry 30 (Suppl 2): 129-134, 1997.

51. Luan L, Wang G and Lin R: Studies on the chemical constituents of extract with water from Forsythia suspensa. Zhong Yao Cai 33: 220-221, 2010 (In Chinese).

52. Yang YB, Yang Y, Li X, Yang Z, Wu ZJ, Zheng YL and Sun LN: Studies on the chemical constituents of Chaenomeles speciosa. Zhong Yao Cai 32: 1388-1390, 2009 (In Chinese).

53. Psahoulia FH, Moumtzi S, Roberts ML, Sasazuki T, Shirasawa S and Pintzas A: Quercetin mediates preferential degradation of oncogenic Ras and causes autophagy in Ha-RAS-transformed human colon cells. Carcinogenesis 28: 1021-1031, 2007.

54. Isakson P, Bjørås M, Bøe SO and Simonsen A: Autophagy contributes to therapy-induced degradation of the PML/RARA oncoprotein. Blood 116: 2324-2331, 2010.

55. Hsueh YS, Yen CC, Shih NY, Chiang NJ, Li CF and Chen LT: Autophagy is involved in endogenous and NVP-AUY922induced KIT degradation in gastrointestinal stromal tumors. Autophagy 9: 220-233, 2013. 